\title{
Growing Health and Quality of Life: Benefits of Urban Organic Community Gardens
}

\author{
Paulo Nova $^{{ }^{*}}$, Elisabete Pinto ${ }^{1,3}$, Benedita Chaves ${ }^{2}$ and Margarida Silva ${ }^{1}$ \\ ${ }^{1}$ Universidade Católica Portuguesa, CBQF - Centro de Biotecnologia e Química Fina e Laboratório Associado, Escola \\ Superior de Biotecnologia, Rua Arquiteto Lobão Vital, Apartado 2511, 4202-401 Porto, Portugal
}

${ }^{2}$ LIPOR - Intermunicipal Waste Management of Greater Porto

${ }_{3}^{3}$ ISPUP - Instituto de Saúde Pública da Universidade do Porto. Rua das Taipas n-1354050-600 Porto, Portugal

Received: February 14, 2018; Accepted: March 5, 2018; Published: March 8, 2018

*Corresponding author: Paulo Nova, Rua Emídio Garcia Ramirez, no54, 4450-668 Leça da Palmeira, Portugal, E-mail: paulo_nova3@hotmail. com

\begin{abstract}
Objectives: To characterize the horticulturists of an urban garden in terms of their current state of health and health behaviors (at gardening beginning) and to evaluate the effect of horticulture practice on health behaviors and quality of life (after a six month gardening stretch).

Introduction: The way in which cities have grown, with heavy air and noise pollution, reduced green spaces, a long distance and out of season food based system and limited sunshine access has led to multiple public health challenges. This in turn has prompted the emergence of various local and state policies aimed at improving the health and quality of life of urbanites.
\end{abstract}

Method: Interviews using structured questionnaires were conducted twice with 115 city dwellers: when they got started in a vegetable garden and about 6 months later.

Results: Participants were mainly female (57.8\%), professionally active $(48.0 \%)$ and with a mean age of 53 years. This research showed significant behavioral changes among its users, including positive outcomes in anthropometric parameters, physical activity, smoking habits, eating habits, health status and overall quality of life.

Conclusion: Despite a short follow-up period, it could be shown that gardening did influence health and quality of life behaviors.

Keywords: Behavior Change; Mental Health; Nutrition; Physical Activity/ Exercise; Organic Community Gardens

\section{Introduction}

Currently, 54\% of the world's population lives in urban areas. Continued urbanization, coupled with population growth, will mean an additional 2.5 billion people living in cities by 2050, with about $90 \%$ of those spread throughout Asia and Africa. Urban population worldwide is expected to reach $66 \%$ in the same year [23].

The way in which cities have grown, with heavy air and noise pollution, reduced green spaces, a long distance and out of season food based system and limited sunshine access has led to multiple public health challenges. This in turn has prompted the emergence of various local and state policies aimed at improving the health and quality of life of urbanites [22,24].

Urban growth markedly influenced dietary patterns. The food industry increasingly introduced foods with low nutritional value, high energy density and rich in additives, saturated fats, sugar and cholesterol. These new dietary patterns, coupled with a sedentary lifestyle, are the top risk factors for increases in the prevalence of overweight, obesity, type II diabetes and cardiovascular diseases $[19,16]$.

Urban agriculture is one of the answers available to counter such negative trends, as it allows for the production of healthy and diversified food closer to home and through natural methods of fertilization and pest control. In addition, by creating green areas, environmental balance and public well-being are improved $[2,17]$. A globally positive perception towards urban gardens notwithstanding, studies quantifying their actual effect on users are still scarce. The interest of the scientific community, however, is clearly growing $[11,7]$.

Studies have shown benefits of gardening in symptoms of anxiety and depression in adults with psychological issues, generally improved health, quality of life, strength, endurance, flexibility, increased cognitive ability and socialization in institutionalized elderly people, improvements of physical and psychological health in patients with chronic pain, improvements in patients with mental illness regarding their psychic status and progress in learning and socialization skills and benefits on active aging and stress in horticulturists between 53 and 82 years old $[14,26,25,3,12]$.

However, to the best of our knowledge, there have been no studies that explored in detail, the impact of horticulture on specific health behaviors. If we obtain promising results, we can inforce the role of horticulture in health promotion.

\section{Objectives}

To characterize the horticulturists of an urban garden in terms of their current state of health and health behaviors (at 
gardening beginning) and to evaluate the effect of horticulture practice on health behaviors and quality of life (after a six month gardening stretch [21].

\section{Methods}

\section{Study Design}

This research was conducted in an urban community garden established right before the beginning of the study. The area is part of a mental hospital's larger grounds and sits right in the middle of Porto, Portugal's second largest city. Both hospital workers and residents in surrounding neighborhoods were free to apply for a plot.

The first evaluation took place between July and October 2015, at the moment people were starting their horticultural activity. Follow-up occurred between May and August 2016. The interval between evaluations ranged between six and twelve months, with two thirds of respondents re-evaluated eight to ten months after the initial contact.

\section{Participants}

All plots were visited and their users were invited to participate in the study. Contacts were attempted on at least three different days and on at least three different times of the day (morning, afternoon and evening). If horticulturalists were not avaliable during these attempts they were contacted by phone, again at three different times of day and on three different days (contacts were supplied by the institution in charge of garden management, who is a partner in this study). Those that still were not reached after all these attempts were excluded. Of those contacted, one person declined to be enrolled in the study. A total of 115 people opted in.

Of the initial 115 participants, 102 (88.7\%) were followedup. The 13 participants who dropped out (5 gave up horticulture and 8 remained unavailable) were compared with the remaining regarding their sociodemographic characteristics (age, sex, educational level and professional status), experience in horticulture and motivation to start the garden care project. No statistically significant differences were found between the two groups for any of the variables considered. It is also important to note that garden space is paid for, so, the remaining horticulturists are motivated enough to bear these costs.

\section{Data Collection}

Data was collected using semi-structured questionnaires. These were always applied by the same researcher and during face-to-face or phone-call interviews. The initial questionnaire included the following parameters: personal data, anthropometry (self-reported weight and height, through which the Body Mass Index (BMI) was calculated), health and physical activity (physical activity was assessed based on the European Prospective Investigation into Cancer and Nutrition Physical Activity questionnaire, validated for the Portuguese population, smoking habits and alcohol consumption, expectations (savings in produce purchases, increased organic food use, increased fruit and vegetable use, increased physical activity and improved environmental practices), motivation regarding garden work, health status (assessed using the Short Form 36 (SF36) quality of life assessment scale), sustainability practices and patterns of food consumption [4].

The SF36 questionnaire used comprises eight domains: functional capacity, physical aspects, pain, general health, vitality, social aspects, emotional aspects and mental health. The values obtained in each domain range from 0 to 100 , where 0 is the worst and 100 the best option (RAW scale) $[15,5]$. This instrument was validated for the Portuguese population [10].

Professional activity data were aggregated in groups based on the "Portuguese Job Classification" by the National Statistics Institute [13].

The questionnaire applied at the second evaluation included all the parameters previously described (with the exception of personal data) and added a final chapter on gardening impacts.

\section{Data Analysis}

Categorical variables were described by their absolute (n) and relative (\%) frequencies. Continuous variables were described using means and standard deviation (if they followed the normal distribution), or through medians and percentiles 25 and 75 (if their distribution did not resemble the normal distribution). Comparison of proportions between nominal variables or between a nominal and an ordinal variable was done using the chi-square test or fisher's exact test, as appropriate.

In order to evaluate the normality of the distribution of continuous variables the Kolmogorov-Smirnov test was used. For the comparison of the same variable between the two moments of evaluation, in cases where the variable did not follow the normal distribution, the Wilcoxon test was used for the comparison of ordinal and continuous variables or comparison between an ordinal and continuous variable. The McNemar test was used to test the correlation between the frequencies of the dichotomous nominal variables. The Mann-Whitney test was used to compare two independent groups with respect to ordinal and continuous variables without normal distribution. In order to compare proportions the chi-square was used. The T test was used to compare means between independent samples in cases where the variables complied with normality. A significance level of $5 \%$ was used for all statistical tests. Statistical analysis was performed using the IBM SPSS STATISTICS 23 software for Microsoft Windows.

\section{Results}

\section{Sample Characterization}

The sample consisted mainly of females (57.8\%) with a mean age of 53 years (minimum 24 and maximum 77 years old). A large proportion of the participants were married or in nonmarital partnerships and, in some cases, their children were still part of the household. The educational level of the sample was high, with $52.0 \%$ of the participants holding college degrees and $23.5 \%$ high school degrees. The majority of the participants were from Porto (96.1\%). The remainder lived in Matosinhos (2.9\%) and Maia 
$(1.0 \%)$, two counties in the Porto region.

Regarding the professional status, about half the sample was employed (48.0\%) and a high proportion was retired and/or disabled (38.2\%). When interviewed about household income, an equal proportion of respondents stated that "current income is enough" and "it is very difficult to live on current income" (31.4\%). Regarding occupation, the sample was mainly composed of "specialists in intellectual and scientific activities" (39.2\%) and "technicians and intermediate level professionals" (22.5\%).

The majority of the subjects (52.0\%) had chronic diseases, the most prevalent being hypertension (19.6\%) and type II diabetes (16.7\%). Only $36.3 \%$ of the participants reported having experience in horticulture prior to starting work at that lot. When the study started the majority of respondents (51.0\%) had been exploring their plot for a maximum of three months. About a quarter $(25.5 \%)$ had started gardening in the week prior to the survey.

\section{Anthropometry and Physical Activity}

Regarding the BMI, although slight, there was a statistically significant decrease in this parameter between the two evaluations. The mean differences between the final and the initial BMI were $-0.40 \mathrm{~kg} / \mathrm{m} 2$. Relevant effects were found in the practice, type of activity, frequency and duration of physical activity practices. There was also a considerable increase in the number of people training in the gym. These results are described in Table 1.

Table 1: Anthropometry and Physical Activity Practice $(n=102)$

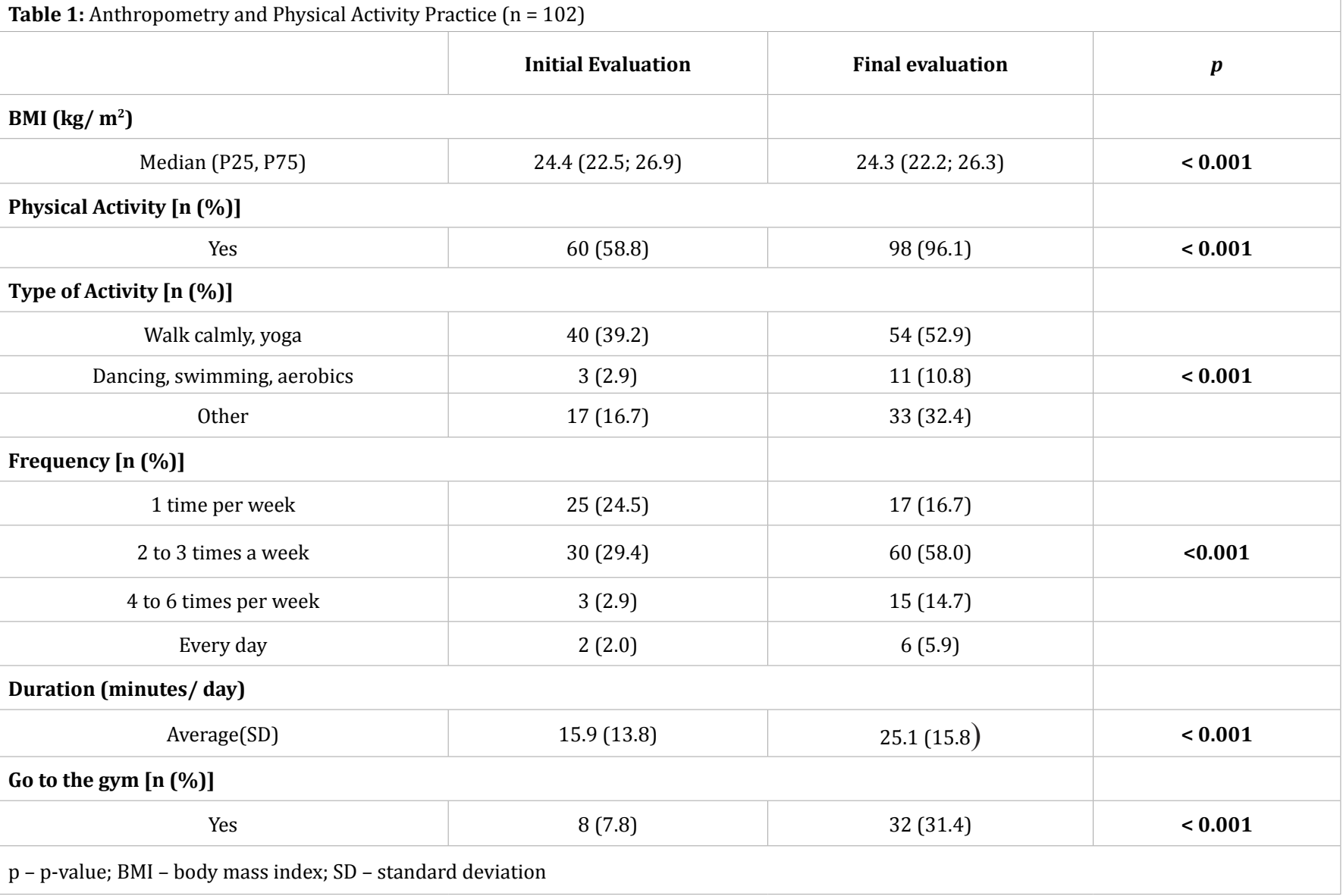

Only four participants practiced a specific sport in the initial evaluation: two of them did martial arts, one gymnastics and the other canoeing. In the final evaluation all these participants carried on with their training, plus another one began to learn martial arts.

\section{Smoking Habits and Alcohol Consumption}

There are significant differences between the initial and the final assessments in terms of smoking habits and number of cigarettes smoked. There were seven participants who quit smoking (nonsmokers went from $65(63.8 \%)$ in the first evaluation to $72(70.6 \%)$ ) and, among smokers, the median number of cigarettes decreased by half (from $20(11 ; 20)$ to $10(8 ; 10))$. There were no significant changes detected in the consumption of alcoholic beverages.

\section{Health Status and Quality of Life}

In the participant re-evaluation it was possible to observe a significant improvement in health status and quality of life in all eight domains measured through the SF-36 scale. On average, the 
improvement in the different domains by the second evaluation was about 20 points on a scale of 0 to 100 (Table 2).

Table 2. Domains of functional capacity, limitation by physical aspects, pain, general health status, vitality, social aspects, limitation by emotional aspects and mental health $(\mathrm{n}=102)$

\begin{tabular}{|c|c|c|c|}
\hline Domains & $\begin{array}{c}\text { Initial } \\
\text { Evaluation }\end{array}$ & $\begin{array}{c}\text { Final } \\
\text { evaluation }\end{array}$ & $\boldsymbol{p}$ \\
\hline & \multicolumn{2}{|c|}{ Mean } \\
(standard deviation) & \\
\hline Functional capacity & $76.9(18.3)$ & $91.7(10.2)$ & $<\mathbf{0 . 0 0 1}$ \\
\hline Physical limitations & $55.5(26.0)$ & $83.2(13.9)$ & $<\mathbf{0 . 0 0 1}$ \\
\hline Pain & $67.0(31.6)$ & $88.5(14.8)$ & $<\mathbf{0 . 0 0 1}$ \\
\hline General health status & $61.2(19.6)$ & $78.7(13.3)$ & $<\mathbf{0 . 0 0 1}$ \\
\hline Vitality & $47.9(9.6)$ & $69.5(14.4)$ & $<\mathbf{0 . 0 0 1}$ \\
\hline Social aspects & $57.8(25.7)$ & $76.0(13.8)$ & $<\mathbf{0 . 0 0 1}$ \\
\hline Emotional limitations & $64.9(25.0)$ & $82.8(13.5)$ & $<\mathbf{0 . 0 0 1}$ \\
\hline Mental health & $57.5(16.0)$ & $77.6(11.5)$ & $<\mathbf{0 . 0 0 1}$ \\
\hline
\end{tabular}

\section{Eating Habits}

Statistically significant differences were found in the frequency of consumption of all food groups studied, with the exception of the meat group. For dairy products, fish, vegetables in the main dish or in soup, fresh fruit, natural fruit juices and culinary herbs a consumption increase was detected. For the "potato, rice and pasta" group and the "pastries and sweets" group there was a decrease in consumption. For the "bread and cereal" group, although there are significant differences, the trend is not clear (Table 3).

\section{Subjective Assessment of Impacts and Influences}

All participants reported that gardening had brought positive change into their lives. The specific parameters mentioned were then grouped into categories.

The respondents were also asked if any friend or family member had mentioned that they "looked better", "seemed younger" or any such expression. Of the 102 participants, 72 responded positively. The results are shown in Table 4.

Table 3. Food consumption frequencies $(n=102)$

Initial Evaluation $(\mathrm{n}=102)[\mathrm{n}(\%)]$

\begin{tabular}{|c|c|c|c|c|c|c|c|c|c|}
\hline & $\begin{array}{c}\text { Until } 3 \\
\text { times per } \\
\text { month }\end{array}$ & $\begin{array}{c}1-4 \\
\text { times } \\
\text { per week }\end{array}$ & $\begin{array}{c}5-7 \\
\text { times per } \\
\text { week }\end{array}$ & $\begin{array}{c}\text { More than } \\
\text { once per } \\
\text { day }\end{array}$ & $\begin{array}{c}\text { Until } 3 \\
\text { times per } \\
\text { month }\end{array}$ & $\begin{array}{c}1-4 \\
\text { times per } \\
\text { week }\end{array}$ & $\begin{array}{c}5-7 \text { times } \\
\text { per week }\end{array}$ & $\begin{array}{l}\text { More than once } \\
\text { per day }\end{array}$ & $p$ \\
\hline Dairy Products & $\begin{array}{c}12 \\
(11.8)\end{array}$ & $\begin{array}{c}28 \\
(27.5)\end{array}$ & $\begin{array}{c}37 \\
(36.3)\end{array}$ & $\begin{array}{c}25 \\
(24.5)\end{array}$ & $\begin{array}{c}3 \\
(2.9)\end{array}$ & $\begin{array}{c}7 \\
(6.9)\end{array}$ & $\begin{array}{c}35 \\
(34.3)\end{array}$ & $\begin{array}{c}57 \\
(55.9)\end{array}$ & $<0.001$ \\
\hline Meat & $\begin{array}{c}4 \\
(3.9)\end{array}$ & $\begin{array}{c}59 \\
(57.8)\end{array}$ & $\begin{array}{c}35 \\
(34.3)\end{array}$ & $\begin{array}{c}4 \\
(3.9)\end{array}$ & $\begin{array}{c}3 \\
(2.9)\end{array}$ & $\begin{array}{c}68 \\
(66.7)\end{array}$ & $\begin{array}{c}31 \\
(30.4)\end{array}$ & $\begin{array}{c}0 \\
(0.0)\end{array}$ & 0.100 \\
\hline Fish & $\begin{array}{c}3 \\
(2,9)\end{array}$ & $\begin{array}{c}77 \\
(75.5)\end{array}$ & $\begin{array}{c}17 \\
(16.7)\end{array}$ & $\begin{array}{c}5 \\
(4.9)\end{array}$ & $\begin{array}{c}1 \\
(1.0)\end{array}$ & $\begin{array}{c}19 \\
(18.6)\end{array}$ & $\begin{array}{c}77 \\
(75.5)\end{array}$ & $\begin{array}{c}5 \\
(4.9)\end{array}$ & $<0.001$ \\
\hline $\begin{array}{l}\text { Bread and } \\
\text { Cereals }\end{array}$ & $\begin{array}{l}3 \\
(2.9)\end{array}$ & $\begin{array}{c}10 \\
(9.8)\end{array}$ & $\begin{array}{c}33 \\
(32.4)\end{array}$ & $\begin{array}{c}56 \\
(54.9)\end{array}$ & $\begin{array}{c}2 \\
(2.0)\end{array}$ & $\begin{array}{c}8 \\
(7.8)\end{array}$ & $\begin{array}{c}48 \\
(47.1)\end{array}$ & $\begin{array}{c}44 \\
(43.1)\end{array}$ & $<0.001$ \\
\hline $\begin{array}{c}\text { Potatoes, Rice } \\
\text { and Pasta }\end{array}$ & $\begin{array}{c}0 \\
(0.0)\end{array}$ & $\begin{array}{c}22 \\
(21.6)\end{array}$ & $\begin{array}{c}24 \\
(23.5)\end{array}$ & $\begin{array}{c}56 \\
(54.9)\end{array}$ & $\begin{array}{c}0 \\
(0.0)\end{array}$ & $\begin{array}{c}8 \\
(7.8)\end{array}$ & $\begin{array}{c}35 \\
(34.3)\end{array}$ & $\begin{array}{c}59 \\
(57.8)\end{array}$ & 0.023 \\
\hline $\begin{array}{l}\text { Vegetables in } \\
\text { Main Dish }\end{array}$ & $\begin{array}{c}9 \\
(8.8)\end{array}$ & $\begin{array}{c}52 \\
(51.0)\end{array}$ & $\begin{array}{c}33 \\
(32.4)\end{array}$ & $\begin{array}{c}8 \\
(7.8)\end{array}$ & $\begin{array}{c}0 \\
(0.0)\end{array}$ & $\begin{array}{c}2 \\
(2,0)\end{array}$ & $\begin{array}{c}41 \\
(40.2)\end{array}$ & $\begin{array}{c}59 \\
(57.8)\end{array}$ & $<0.001$ \\
\hline $\begin{array}{l}\text { Vegetables in } \\
\text { Soup }\end{array}$ & $\begin{array}{c}18 \\
(17.6)\end{array}$ & $\begin{array}{c}51 \\
(50.0)\end{array}$ & $\begin{array}{c}31 \\
(30.4)\end{array}$ & $\begin{array}{c}2 \\
(2,0)\end{array}$ & $\begin{array}{c}0 \\
(0.0)\end{array}$ & $\begin{array}{c}31 \\
(25.8)\end{array}$ & $\begin{array}{c}61 \\
(50.8)\end{array}$ & $\begin{array}{c}10 \\
(9.8)\end{array}$ & $<0.001$ \\
\hline Fresh Fruit & $\begin{array}{c}9 \\
(8.8)\end{array}$ & $\begin{array}{c}33 \\
(32.4)\end{array}$ & $\begin{array}{c}43 \\
(42.2)\end{array}$ & $\begin{array}{c}17 \\
(16.7)\end{array}$ & $\begin{array}{c}0 \\
(0.0)\end{array}$ & $\begin{array}{c}5 \\
(4.2)\end{array}$ & $\begin{array}{c}27 \\
(26.5)\end{array}$ & $\begin{array}{c}70 \\
(68.6)\end{array}$ & $<0.001$ \\
\hline $\begin{array}{l}\text { Natural Fruit } \\
\text { Juices }\end{array}$ & $\begin{array}{c}67 \\
(65.7)\end{array}$ & $\begin{array}{c}34 \\
(33.3)\end{array}$ & $\begin{array}{c}1 \\
(1.0)\end{array}$ & $\begin{array}{c}0 \\
(0.0)\end{array}$ & $\begin{array}{c}35 \\
(34.3)\end{array}$ & $\begin{array}{c}63 \\
(61.8)\end{array}$ & $\begin{array}{c}4 \\
(3.9)\end{array}$ & $\begin{array}{c}0 \\
(0.0)\end{array}$ & $<0.001$ \\
\hline Culinary Herbs & $\begin{array}{c}32 \\
(31.4)\end{array}$ & $\begin{array}{c}48 \\
(47.1)\end{array}$ & $\begin{array}{c}19 \\
(18.6)\end{array}$ & $\begin{array}{c}3 \\
(2.9)\end{array}$ & $\begin{array}{c}0 \\
(0.0)\end{array}$ & $\begin{array}{c}10 \\
(9.8)\end{array}$ & $\begin{array}{c}51 \\
(50.0)\end{array}$ & $\begin{array}{c}41 \\
(40.2)\end{array}$ & $<0.001$ \\
\hline
\end{tabular}


Table 4. Self-perceived and third party perception of gardening benefits ( $n=102)$

\begin{tabular}{|c|c|}
\hline Self-perception & [n (\%)] \\
\hline Physical well-being & $31(30.4)$ \\
\hline Emotional well-being & $62(60.8)$ \\
\hline Dietary intake & $49(48.0)$ \\
\hline Socialization & $25(24.5)$ \\
\hline Physical activity & $22(21.6)$ \\
\hline Smoking habits & $8(7.8)$ \\
\hline Savings & $4(3.9)$ \\
\hline Third party perception & {$[\mathbf{n}(\%)]$} \\
\hline You look good and happier & $25(24.5)$ \\
\hline You look better & $15(14.7)$ \\
\hline You look healthier & $11(10.8)$ \\
\hline You're much more excited about life & $7(6.9)$ \\
\hline It looks like you're 10 years younger & $4(3.9)$ \\
\hline You're in shape - You look younger & $4(3.9)$ \\
\hline You are much more active & $2(2.0)$ \\
\hline You seem happier & $2(2.0)$ \\
\hline Lately you are calmer, more serene & $1(1.0)$ \\
\hline You are thinner and look good & $1(1.0)$ \\
\hline
\end{tabular}

Impact of Exposure Duration on Behavioral Improvement, Quality of Life, Health and Anthropometry

In order to understand whether dedicating more time to vegetable gardening enhanced the behavioral and anthropometric improvements, participants were divided into two distinct groups: those that invested up to 3 hours a week and those who spent more than 3 hours a week in their allotment. The first group consisted of 42 gardeners (41.2\%) and the second group of $60(58.8 \%)$.

For most variables (BMI, physical activity, type of activity, frequency, duration, gym attendance, smoking habits, alcoholic beverages and SF36 questionnaire domains) there were no statistically significant differences between the two groups. Regarding food frequencies significant differences were found between the two groups for "vegetables in soup", "natural fruit juices" and "culinary herbs", with horticulturists with an extended commitment showing increased consumption.

\section{Discussion}

The present study suggests that the practice of horticulture is associated with multiple benefits, ranging from improved health behaviors, improvement in the perception of health status and general quality of life. Furthermore, larger gardening time was not associated with better outcomes for most of the variables studied, meaning these advantages are readily available to all gardeners.

The study was carried out in an urban community garden where most participants were middle-aged women, and approximately half $(48.0 \%)$ were professionally active with higher education (52.0\%). This specific profile can be understood through the criteria used for allocating plots, which gives priority to those working at the hospital on whose grounds the garden is located. This proximity allows for increased presence and gardening work.

Despite a relatively young and professionally active sample, it is noteworthy that $52.0 \%$ of participants were suffering from at least one chronic pathology. It is well known that in Portugal we have been able to "give years to life, but not life to those years" meaning that people reach older ages but suffer from an increase in disabilities and comorbidities. EUROSTAT data for the year 2014 indicate that healthy life expectancy in Portugal is only 58.3 years for males and 55.4 years for females [9]. In addition, since our data about morbidity was self-reported, it could be underestimated. Arterial hypertension, for example, is reported by only $19.6 \%$ of the participants even though the prevalence in the Portuguese adult population is $42.6 \%$ [6]. On the other hand, type II diabetes is at $16.7 \%$ in our sample whereas the Portuguese adult population is a lower $12.4 \%$ [18]. This likely is not an overestimation, but an actual deviation from the national pattern.

Regarding body composition, significant differences were found for BMI, with median values lower in the final evaluation. These values point towards a general loss of weight in the participants. Although this difference is tenuous, it is also very positive, since the initial median of BMI was close to the upper limit of normality. So, the practice of horticulture seems to help normalize weight. It is reasonable to speculate that longer term horticultural practice may lead to increased differences. These results are in line with the study by who performed a BMI analysis of 198 horticulturalists and found a reduction in BMI values in both sexes and in all cases, as compared to appropriate controls [28]. They also showed that horticulturists were less likely to be overweight or obese when compared to neighbors. Results were significantly more relevant than in the present investigation, which likely resulted from the longer gardening period (between one and nine years).

Physical activity also registered meaningful positive changes. A large proportion of individuals (37.3\%) started engaging in physical activity, with a significant increase in workout frequency and duration. The increase in individuals who began walking is remarkable, and is at least partly due to the trips to and from the garden. Gym attendance followed the same trend, with a remarkable increase of 24 individuals starting practice. It is plausible that the garden activity started a positive snowball, branching out into various other sports.

Wells et al, who studied the influence of green spaces in school environment on the physical activity of primary school children, found a reduction in the sedentary lifestyle associated with access to green areas [27]. Despite major differences in the sociodemographic profiles, the present study also points toward green space availability as a factor in physical activity levels. Similarly, 
in a physical activity comparison between horticulturalists and non horticulturalists over 50, concluded non gardeners were three times more likely to self report as "quite inactive" [20].

For smoking habits the results were also very encouraging: seven participants stopped smoking and the median number of cigarettes decreased by half in smokers. There were visible improvements in health behaviors, supporting the assumption that horticulture can promote the adoption of salutogenic habits. To the best of our knowledge this is the first time the connection between horticulture and smoking/alcohol behavior has been established - more research is definitely needed to further explore the relationship.

At the end of the study the consumption of fruit and vegetables was significantly higher, the same happening to interest in organic food. The SF-36 measuring self-perception of the health status and quality of life identified an improvement in all dimensions evaluated. Such results corroborate previous work evidencing how gardening brings with it better health and quality of life for participants $[14,26,3,12]$. The work of testing the value of a horticultural component in a chronic pain management program also used the SF-36 questionnaire and obtained equally encouraging results [25].

Eating habits in horticulturalists clearly tilted toward improvement, with a reduction in the sweets and pastries group and an increase in the frequency of vegetables, fruits and herbs consumption. This is in alignment with previous work which measured increases in fruits and vegetables consumption among schoolchildren given the opportunity to start gardening $[8,1]$.

Vegetables self production boosts availability and clearly influences participants food choices, which go well beyond the produce grown. For example, an increase in the consumption of dairy products and fish was detected together with a reduction in potatoes, rice and pasta use.

The use of aromatic herbs was the one variable where more dedicated horticulturalists (those spending over three hours per week) reaped more benefit. Clearly going by the garden more often seems to increase the opportunities for harvesting and cooking.

Some methodological aspects in this study contribute to data reliability. One of them was the fact that both assessments were carried out during gardening appropriate months: the first during summer/early fall and the second at springtime. Also there were very few losses: almost all horticulturalists initially registered were available at follow-up as well. And because the questionnaire was prepared specifically for this study (and there was a single researcher collecting data) the before and after comparison was more accurate.

Nevertheless, the possibility that some of these results may be inflated due to information bias cannot be ruled out, since the participants, knowing the objectives of the study, may have tried to fit in with the researcher's expectations. In addition, the evaluation period was short. It could happen that the gardening commitment decreases with time, at least with some people.
It should also be noted that the sample studied, because of its profile, is not necessarily representative of other community gardens. These characteristics will certainly influence levels of motivation, expectations and the ability to change self behaviors.

\section{Conclusions}

Study results reinforce that a community vegetable garden can induce significant behavioral changes among its users, including positive outcomes in anthropometric parameters, physical activity, smoking habits, eating habits, health status and overall quality of life. Further research is needed to understand why horticulture promotes so many different behavioral changes. However, this will probably have to do with the contact with nature and the impact on physical and mental well-being subsequently causing these individuals to want to do more and better for their health by changing habits that influence it. It is also important to evaluate the impact of exposure duration with more distant moments of analysis because in variables more "directly influenced" by horticulture such as food consumption of vegetables, fruit juices and aromatic herbs were registered relevant differences.

These results open important ramifications in public health since urban gardens can help revert multiple negative urban trends with a low tech, low cost, noninvasive approach that can be replicated in a majority of countries.

\section{Human Participant Protection}

The Ethics Lab of Católica Porto Institute of Bioethics Committee and the Institutional review board approved this study (ERS number: 10/ 2015).

\section{Funding}

This research received no specific grant support from any funding agency in the public, commercial, or not-for-profit sectors.

\section{References}

1. Berezowitz CK, Bontrager YA and Schoeller DA. School Gardens Enhance Academic Performance and Dietary Outcomes in Children. J Sch Health. 2015; 85(8): 508-518. doi: 10.1111/josh.12278

2. Boukharaeva L, Marcel Marloie. Family urban agriculture as a component of human sustainable development. CAB Reviews: Perspectives in Agriculture, Veterinary Science, Nutrition and Natural Resources. 2006;1(025).

3. Camargo R, Coelho E, Gundim D, et al. Uso Da Hortoterapia No Tratamento De Pacientes Portadores De Sofrimento Mental Grave. Enciclopédia Biosfera: 2015;3634-3643.

4. Camões M, Severo M, Santos A, Barros H, Lopes C. Testing an adaptation of the EPIC Physical Activity Questionnaire in Portuguese adults: A validation study that assesses the seasonal bias of self-report. Ann Hum Biol. 2010;37(2):185-197. doi: 10.3109/03014460903341836

5. Cardoso P. 2011, A qualidade de vida no indivíduo com perda auditiva. Repositório Científico do Instituto Politécnico do Porto ESTSP - Escola Superior de Tecnologia da Saúde do Porto.

6. Cortez-dias N, Martins S, Belo A. Prevalence and treatment patterns of arterial hypertension in primary health care in Portugal. VALSIM Study Results. Rev Port Cardiol. 28(5): 499-523. 
7. Davies G DM, Lennartsson M, Schmutz U e Williams S. The benefits of gardening and food growing for health and wellbeing. Garden Organic and Sustain. 2014.

8. Duncan MJ, Eyre E, Bryant E, Clarke N, Birch S, Staples V. The impact of a school-based gardening intervention on intentions and behaviour related to fruit and vegetable consumption in children. J Health Psychol. 2015;20(6):765-773. doi: 10.1177/1359105315573445

9. EUROSTAT. Your Key to European Statistics. Healthy Life Years and Life Expectancy at Birth by sex 2015.

10. Ferreira P. Measuring the State of Health: Creation of the Portuguese Version of MOS SF-36. Center for Studies and Research in Health of the University of Coimbra. 1998.

11. Fried G, Wichrowski M, Chambers N. The Glass Garden: A Therapeutic Garden in New York City: Arena Books Associates (2014).

12. Hawkins J, Mercer J and Clayton D. Growing a Healthy Older Population in Wales: Project summary and key findings. National Institute for Social Care and Health Research. 2013.

13. INE - Instituto Nacional de Estatística. (2010) Classificação Portuguesa das Profissões 2010: Lisboa. Portugal.

14. Clatworthy, J, Hinds J and Camic PM. Gardening as a mental health intervention: a review. Mental Health Review Journal. 2014; 18: 214 225

15. Jenkinson C, Stewart-Brown S, Petersen S, C. Paice. Assessment of the SF-36 version 2 in the United Kingdom. J Epidemiol Community Health. 1999; 53(1): 46-50

16. Mancini M, et al. Obesity and Associated Diseases. Treaty of Obesity. Itapevi. 2010, AC Pharmaceutical.

17. Nowak DJ, Crane DE and Stevens JC. Air pollution removal by urban trees and shrubs in the United States. Urban Forestry \& Urban Greening. 2006;4(3-4):115-123.

18. National Diabetes Observatory. Diabetes: Facts and Figures 2011. 2010; Annual report of the National Diabetes Observatory.
19. Popkin BM. Global Nutrition Dynamics: the World is Shifting Rapidly toward a Diet Linked with noncommunicable Diseases. Am J Clin Nutr. 2006;84(2): 289-298.

20. Sommerfeld AJ, Waliczek MT, Jayne M Zajicek. Growing Minds: Evaluating the Effect of Gardening on Quality of Life and Physical Activity Level of Older Adults. HortTechnology. 2010;20(4):705-710.

21. Stigsdotter U. A garden at your workplace may reduce stress. 2004;147-157 (Design and Health III - Health Promotion through Environmental International Academy for Design and Health).

22. Su M, Fath BD, Yanga Z. Urban ecosystem health assessment: a review. Sci Total Environ. 2010;408(12):2425-2434. doi: 10.1016/j. scitotenv.2010.03.009

23. United Nations. Department of Economic and Social Affairs, Population Division (2014) World Urbanization Prospects: The 2014 Revision. Highlights: 352.

24. United Nations, Department of Economic and Social Affairs, Population Division World Population Prospects: The 2015 Revision, Key Findings and Advance Tables. 241

25. Verra ML, Angst F, Beck T, Lehmann S, Brioschi R, Schneiter R, et al. Horticultural therapy for patients with chronic musculoskeletal pain: Results of a pilot study. Altern Ther Health Med. 2012;18(2):44-50.

26. Wang D, MacMillan T. The Benefits of Gardening for Older Adults: A Systematic Review of the Literature. Activities, Adaptation \& Aging. 2013;37(2): 153-181.

27. Wells NM, Myers BM and Henderson CR. School gardens and physical activity: A randomized controlled trial of low-income elementary schools. Prev Med. 2014;69: S27-S33. doi: 10.1016/j. ypmed.2014.10.012

28. Zick CD, Smith KR, Kowaleski-Jones L, Uno C, Merrill BJ. Harvesting more than vegetables: the potential weight control benefits of community gardening. Am J Public Health. 2013;103(6): 1110-1115. doi: 10.2105/AJPH.2012.301009 